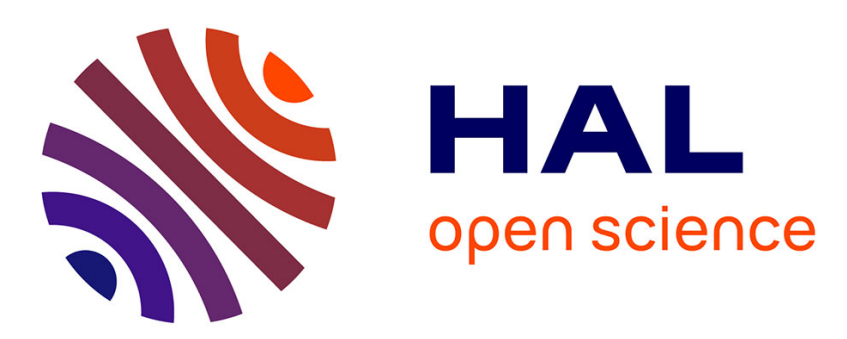

\title{
Comparative Analysis of Control Techniques for Efficiency Improvement in Electric Vehicles
}

\author{
Abdelhakim Haddoun, Mohamed Benbouzid, Demba Diallo, Rachid
}

Abdessemed, Jamel Ghouili, Kamel Srairi

\section{- To cite this version:}

Abdelhakim Haddoun, Mohamed Benbouzid, Demba Diallo, Rachid Abdessemed, Jamel Ghouili, et al.. Comparative Analysis of Control Techniques for Efficiency Improvement in Electric Vehicles. IEEE VPPC'07, Sep 2007, Arlington, United States. pp.629-634. hal-00527620

\section{HAL Id: hal-00527620 \\ https://hal.science/hal-00527620}

Submitted on 19 Oct 2010

HAL is a multi-disciplinary open access archive for the deposit and dissemination of scientific research documents, whether they are published or not. The documents may come from teaching and research institutions in France or abroad, or from public or private research centers.
L'archive ouverte pluridisciplinaire HAL, est destinée au dépôt et à la diffusion de documents scientifiques de niveau recherche, publiés ou non, émanant des établissements d'enseignement et de recherche français ou étrangers, des laboratoires publics ou privés. 


\title{
Comparative Analysis of Control Techniques for Efficiency Improvement in Electric Vehicles
}

\author{
A. Haddoun1,2, M.E.H. Benbouzid1, D. Diallo3, R. Abdessemed4, J. Ghouili5 and K. Srairi6 \\ ${ }^{1}$ Laboratoire d'Ingénierie Mécanique et Electrique (LIME), University of Western Brittany \\ Rue de Kergoat - CS 93837, 29238 Brest Cedex 03, France \\ Phone: +332980180 07; Fax: +332980166 43; E-m@il: m.benbouzid@ieee.org \\ ${ }^{2}$ Electrical Engineering Department, University of Oum El Bouaghi, 04000 Oum El Bouaghi, Algeria \\ ${ }^{3}$ LGEP/SPEE labs, CNRS UMR 8507, Supélec; Univ. Pierre et Marie Curie P6; Univ. Paris Sud P11, 91192 Gif-Sur-Yvette, France \\ ${ }^{4}$ Electrical Engineering Department, University of Batna, Batna, Algeria \\ ${ }^{5}$ GRET Research Group, Engineering Faculty, University of Moncton, Moncton, New Brunswick, Canada \\ ${ }^{6}$ Electrical Engineering Department, University of Biskra, Biskra, Algeria
}

\begin{abstract}
This paper presents system analysis, modeling and simulation of an Electric Vehicle (EV) with three different control strategies: Field Oriented Control (FOC), Direct Torque Control (DTC), and DTC using Space Vector Modulation (DTCSVM). The objective is to assess the control strategy impact on the EV efficiency taking into account the vehicle dynamics. Indeed, among EV motor electric propulsion features, the energy efficiency is a basic characteristic that is influenced by vehicle dynamics and system architecture. Simulation tests have been carried out on a $37-\mathrm{kW}$ EV that consists in an induction motor with a three-level IGBT inverter. Preliminary results seem to indicate that the DTC-SVM scheme is the best candidate.
\end{abstract}

Keywords-Electric vehicle, induction motor, efficiency, field oriented control, Direct torque control, space vector modulation.

\section{INTRODUCTION}

Electric vehicles are set to improve the energy and environmental impact of an increasing road transport population by offering a more energy efficient and less polluting drive-train alternative to conventional internal combustion engine vehicles. So the electric vehicle production is expected to increase dramatically these years. The electric propulsion system is the heart of EV [1]. It consists of the motor drive, transmission device, and wheels. In fact, the motor drive, comprising of the electric motor, power converter, and electronic controller, is the core of the EV propulsion system. The motor drive is configured to respond to a torque demand set by the driver. Many researches [2-3] have demonstrated the induction motor is one of the right electric motor candidates for the most EVs due to its low cost, robustness, highly reliable and free from maintenance.

However, induction motors constitute a theoretically challenging control problem since the dynamical system is nonlinear, the electric rotor variables are not measurable, and the physical parameters are most often imprecisely known. In addition, unlike the traditional industrial setting, in which the induction motor operates mostly at steady state, the EV applications require high performance control of electric motors to obtain fast transient responses and energy efficiency. Important characteristics of an EV motor include good drive control and fault tolerance, as well as low noise with high efficiency. The control of the induction motor for EVs has attracted much attention in the past five years; especially the speed sensorless control of induction motors has been a popular area due to its low cost and strong robustness [3].

In recent years, FOC induction motor drives have greatly increased. In parallel, a number of studies have been developed to find out different solutions for the control of the induction motor drives with two objectives, namely achievement of a precise and quick control of the field motor and torque like in FOC drives, and reduction of the complexity of the algorithms involved in a FOC control.

Among the various proposals, DTC is an entirely different approach to induction motor torque control that was developed to overcome FOC relatively poor transient response and reliance on induction motor parameters. However, beside some attractive features such as fast dynamic response, low sensitivity to parameter changes, lack of internal current control loops and inherently motion sensorless operation [4-5] there exist some problems associated with DTC, namely: difficult to start and low-speed operation, high current and torque ripple, variable switching frequency and high nose level, violence of polarity consistency rules (to avoid \pm 1 switching over dc-link voltage), as well as high sampling frequency needed for digital implementation of hysteresis controllers. Most of above difficulties can be eliminated when instead of the hysteresis controllers with switching table a linear PI controller with a voltage pulse width modulator (PWM) are used. The PI controllers calculate the required stator voltage vector, averaged over a sampling period. The voltage vector is finally synthesized by a PWM technique, which in most cases is the space vector modulation (SVM). Therefore, contrary to the conventional DTC solution, in a DTC-SVM scheme the switching harmonics are neglected in the control algorithm [6].

This paper presents then three different control methods for EVs propulsion in order to achieve the propulsion optimized efficiency. 


\section{VEHICLE MODEL}

Compared to previous works, the proposed control strategy takes into account the vehicle aerodynamics, and is not applied to the sole induction motors. This model is based on the principles of vehicle mechanics and aerodynamics [7]. The total tractive effort is then given by

$F_{t e}=F_{r r}+F_{a d}+F_{h c}+F_{l a}+F_{w a}$

Where $F_{r r}=$ is the rolling resistance force;

$F_{a d}=$ is the aerodynamic drag;

$F_{h c}=$ is the hill climbing force;

$F_{l a}=$ is the force required to give linear acceleration;

$F_{w a}=$ is the force required to give angular acceleration to the rotating motor.

It should be noted that $F_{l a}$ and $F_{w a}$ will be negative if the vehicle is slowing down and that $F_{h c}$ will be negative if it is going downhill. The power required to drive a vehicle at a speed $v$ has to compensate counteracting forces.

$P_{t e}=v F_{t e}=v\left(F_{r r}+F_{a d}+F_{h c}+F_{l a}+F_{w a}\right)$

The efficiency of the motor and its controller are usually considered together, as it is more convenient to measure the efficiency of the whole system. We saw that motor efficiency varies considerably with power, torque, and also motor size [8]. The efficiency is quite well modeled by

$\eta_{m}=\frac{T \omega}{T \omega+k_{c} T^{2}+k_{i} \omega+k_{\omega} \omega^{3}+C}$

Where $k_{c}$ is the copper losses coefficient, $k_{i}$ is the iron losses coefficient, $k_{w}$ is the windage loss coefficient and $C$ represents the constant losses that apply at any speed. Table 1 shows typical values for these constants for two motors that are likely candidates for use in electric vehicles.

Table 1. Typical values for the parameters of (3).

\begin{tabular}{ccc}
\hline Parameters & $\begin{array}{c}\text { Lynch type PM motor, } \\
\text { with brushes, } 2-5 \mathrm{~kW}\end{array}$ & $\begin{array}{c}100 \mathrm{~kW} \text {, high speed } \\
\text { induction motor }\end{array}$ \\
\hline$k_{c}$ & 1.5 & 0.3 \\
$k_{i}$ & 0.1 & 0.01 \\
$k_{\omega}$ & $10^{-5}$ & $5.0 \times 10^{-6}$ \\
\hline$C$ & 20 & 600 \\
\hline
\end{tabular}

\section{CONTROL METHODS}

A number of different control schemes for accurate torque control of an induction motor for this electric vehicle application, have been investigated. FOC and DTC were chosen for simulation, as they are standard induction motor control techniques. An improvement to DTC is DTC-SVM, a new torque control scheme that is also simulated.

\section{A. Nomenclature}

$V_{d s}\left(V_{q s}\right)=d$-axis ( $q$-axis) stator voltages;

$i_{d s}\left(i_{q s}\right)=d$-axis $q$-axis) stator currents; $\lambda_{d r}\left(\lambda_{q r}\right)=d$-axis ( $q$-axis) rotor flux linkages;

$R_{s}\left(R_{r}\right) \quad=$ Stator (rotor) resistance;

$L_{s}\left(L_{r}\right) \quad=$ Stator (rotor) inductance;

$L_{m} \quad=$ Magnetizing inductance;

$L_{\sigma} \quad=$ Leakage inductance $\left(L_{\sigma}=L_{s}-L_{m}{ }^{2} / L_{r}\right)$;

$\omega_{e}\left(\omega_{r}\right)=$ Stator (rotor) electrical speed;

$\Omega \quad=$ Rotor speed $\left(\omega_{r} / \mathrm{p}\right) ;$

$\omega_{s l} \quad=$ Slip frequency, $\omega_{s l}=\omega_{s}-\omega_{r}$

$B=$ Motor damping ratio;

$p \quad=$ pole-pair number.

$$
\left\{\begin{array}{l}
k_{1}=\frac{R_{s}}{L_{\sigma}}+\frac{R_{r} L_{m}^{2}}{L_{r}^{2} L_{\sigma}}, k_{2}=\frac{R_{r} L_{m}}{L_{r}^{2} L_{\sigma}}, k_{3}=\frac{L_{m}}{L_{r} L_{\sigma}}, \\
k_{4}=\frac{R_{r} L_{m}}{L_{r}}, k_{5}=\frac{R_{r}}{L_{r}}, k_{6}=\frac{1}{L_{\sigma}}, k_{t}=\frac{3}{2} p \frac{L_{m}}{L_{r}}
\end{array}\right.
$$

\section{B. FOC}

Generally, dynamic modeling of an induction motor drive is based on rotating reference-frame theory and a linear technique. A system configuration of an induction motor drive is shown in Fig. 1. This motor drive consists of an induction motor, a bang-bang current-controlled pulse width modulated (PWM) inverter, a field-orientation mechanism, a coordinate translator and a speed controller. The electrical dynamics of an induction motor in the synchronously rotating reference frame ( $d$ - $q$-axis) can be expressed by (4-6) [9-10].

$\frac{d}{d t}\left[\begin{array}{l}i_{d s} \\ i_{q s} \\ \lambda_{d r} \\ \lambda_{q r}\end{array}\right]=\left[\begin{array}{cccc}-k_{1} & \omega_{e} & k_{2} & \omega_{r} k_{3} \\ -\omega_{e} & -k_{1} & -\omega_{r} k_{3} & k_{2} \\ k_{4} & 0 & -k_{5} & \omega_{s l} \\ 0 & k_{4} & -\omega_{s l} & -k_{5}\end{array}\right]\left[\begin{array}{l}i_{d s} \\ i_{q s} \\ \lambda_{d r} \\ \lambda_{q r}\end{array}\right]+k_{6}\left[\begin{array}{l}V_{d s} \\ V_{q s} \\ 0 \\ 0\end{array}\right]$

$\frac{d \omega_{r}}{d t}=-\frac{B}{J} \omega_{r}-\frac{1}{J}\left(T_{m}-T_{L}\right)$

$T_{m}=k_{t}\left(\lambda_{d r} i_{q s}-\lambda_{q r} i_{d s}\right)$

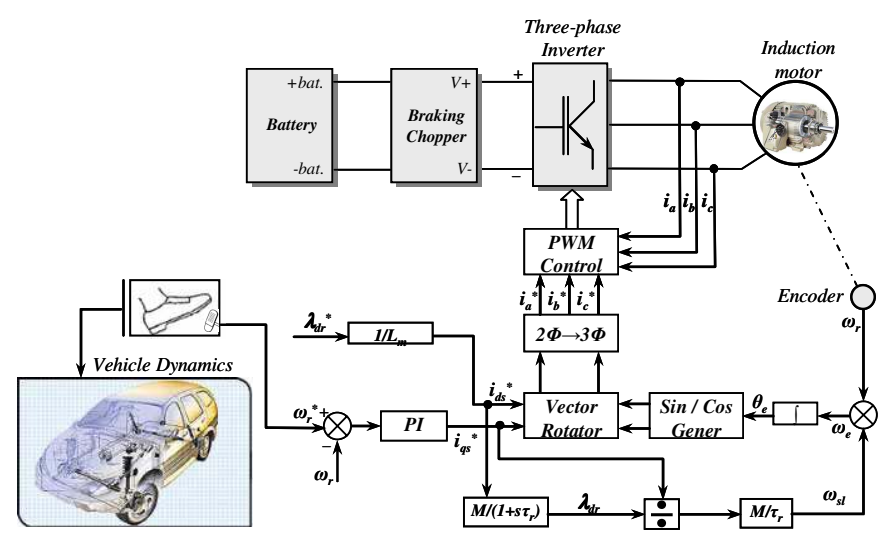

Fig. 1. Direct field-oriented induction motor drive. 


\section{DTC}

The basic idea of the method is to calculate flux and torque instantaneous values only from the stator variables. Flux, torque, and speed are estimated. The input of the motor controller is the reference speed, which is directly applied by the pedal of the vehicle. Control is carried out by hysteresis comparators and a switching logic table selecting the appropriate voltage inverter switching configurations [7], [11]. Figure 2 gives the global configuration of a DTC scheme and also shows how the EV dynamics will be taken into account. The induction motor mechanical equation is as follows.

$J \frac{d \omega_{r}}{d t}+T_{B}+T_{L}=T_{m}$

The induction motor stator flux can be estimated by

$$
\left\{\begin{array}{l}
\lambda_{d s}=\int\left(V_{d s}-R_{s} i_{d s}\right) d t \\
\lambda_{q s}=\int\left(V_{q s}-R_{s} i_{q s}\right) d t \\
\left|\lambda_{s}\right|=\sqrt{\lambda_{d s}^{2}+\lambda_{q s}^{2}} \\
\theta_{\lambda s}=\tan ^{-1}\left(\frac{\lambda_{q s}}{\lambda_{d s}}\right)
\end{array}\right.
$$

Then, the electromagnetic torque is estimated using

$$
T_{m}=\frac{3}{2} \frac{p}{2}\left(\lambda_{d s} i_{q s}-\lambda_{q s} i_{d s}\right)
$$

\section{DTC-SVM}

With the development of microprocessors and DSP techniques, the SVM technique has become one of the most important PWM methods for Voltage Source Inverter (VSI) since it gives a large linear control range, less harmonic distortion, fast transient response, and simple digital implementation [12-13].

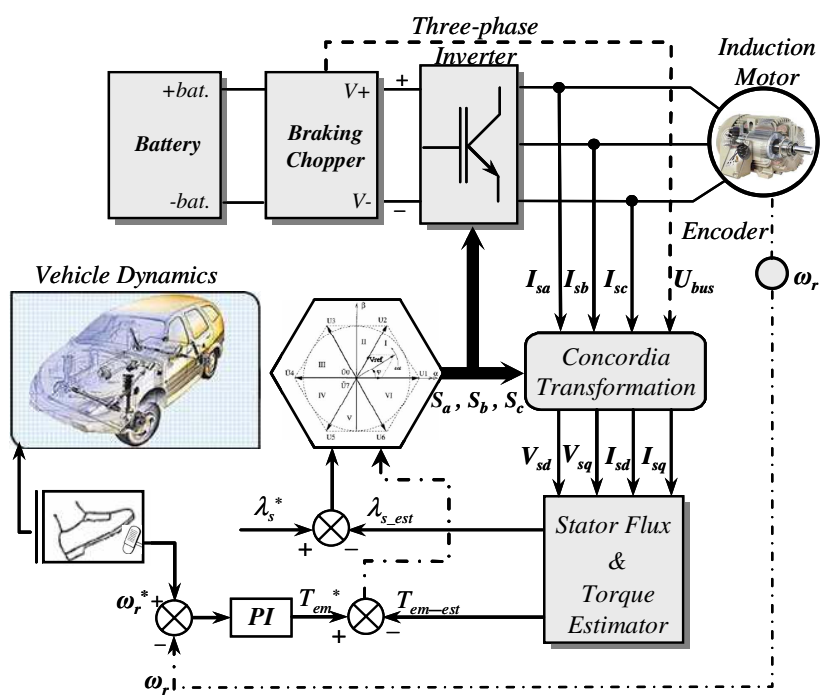

Fig. 2. DTC block diagram.
The SVM principle is based on the switching between two adjacent active vectors and two zero vectors during one switching period. It uses the space vector concept to compute the duty cycle of the switches. Fig. 3 shows a scheme of a three-phase two-level inverter with a star-connection load.

From Fig.3, the output voltages of the inverter can be composed by eight states $u_{0}, u_{1} \ldots u_{7}$, corresponding to the switch states $S_{0}(000), S_{1}(100), \ldots . . S_{7}(111)$, respectively. These vectors can be plotted on the complex plane $(\alpha-\beta)$ as shown in Fig.4, and are given by [3]

$u_{k}= \begin{cases}\frac{2}{3} V_{d c} e^{j(k-1)(\pi / 3)} & \text { for } \quad k=1,2 \ldots .6 \\ 0 & \text { for } k=0,7\end{cases}$

The rotating voltage vector within the six sectors can be approximated by sampling the vector and switching between different inverter states during the sampling period [13]. The vector $u_{S}$ is commonly split into two nearest adjacent voltage vectors and zero $u_{0}$ and $u_{7}$ in an arbitrary sector. For example, during one sampling interval, vector $u_{S}$ in sector I can be expressed as

$u_{S}(t)=\frac{T_{0}}{T_{S}} u_{0}+\frac{T_{1}}{T_{S}} u_{1}+\frac{T_{2}}{T_{S}} u_{2}+\frac{T_{7}}{T_{S}} u_{7}$

Where $T_{0}, T_{1}, T_{2}, T_{7}$ are the turn-on time of the vectors $u_{0}$, $u_{1}, u_{2}, u_{7}$; and $T_{S}$ is the sampling time. $T_{S}-T_{1}-T_{2}=T_{0}+T_{7} \geq$ $0, T_{0} \geq 0$ and $T_{7} \geq 0$.

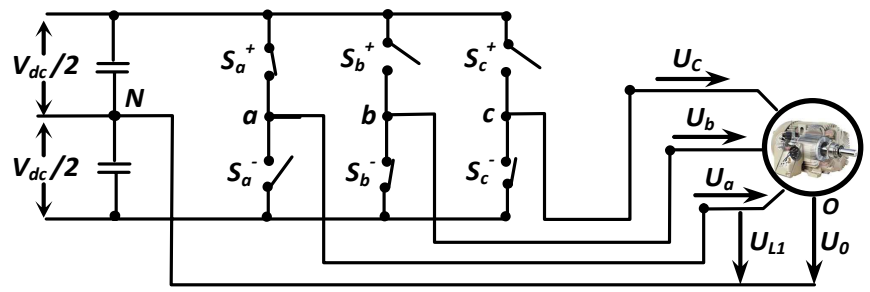

Fig. 3. Three-phase two-level inverter.

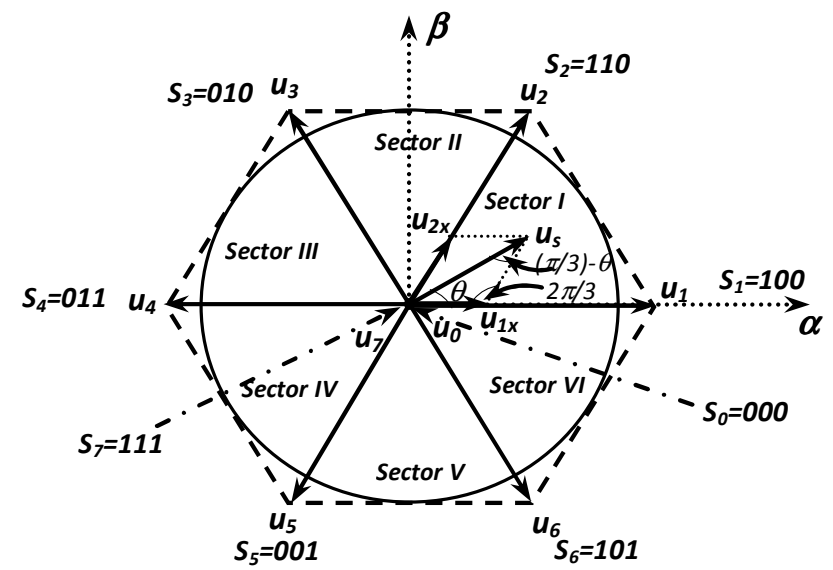

Fig. 4. Space vectors. 
The block diagram of the DTC-SVM control scheme for voltage source inverter-fed IM is shown in Fig. 5 [14]. In this method two PI controllers are used for torque and flux regulation. The outputs of the PI flux and torque controllers generate the reference stator voltage components $U_{s d}, U_{s q}$ expressed in the stator flux oriented coordinates $(d-q)$. These components are dc voltage commands and then transformed into stationary coordinates $(\alpha-\beta)$ the commanded values $U_{s \alpha}, U_{s \beta}$ are delivered to space vector modulator (SVM), which generates switching signals $S_{a}, S_{b}, S_{c}$ for power transistors. [3-6]

\section{SIMULATION RESULTS}

Numerical simulations have been carried out, on an EV propelled by $37-\mathrm{kW}$ induction motor drives. The objectives of the carried out simulations are to assess the efficiency and dynamic performances of the different control strategies. The test cycle is the urban ECE-15 + sub-urban cycle (Fig. 6).

Regarding the obtained results shown by Figs 7 to 8, DTC techniques exhibit improved transient torque response compared to standard rotor flux FOC. The disadvantage of the compared schemes is increased current distortion, resulting in increased motor losses. DTC-SVM is an exception that exhibit low current distortion and also fast torque response and low torque ripple. Therefore, these results seem to indicate that the DTC-SVM scheme is the best candidate for an EV drive optimized control.

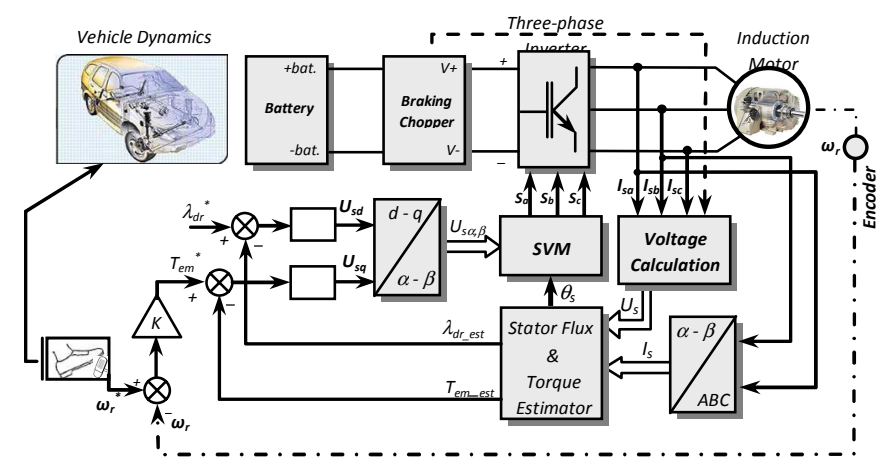

Fig. 5. DTC-SVM block diagram.

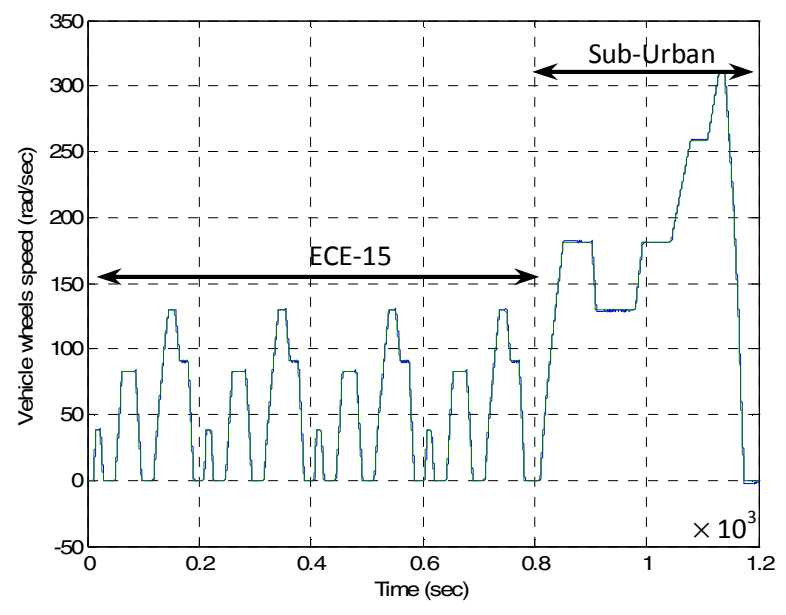

Fig. 6. (ECE-15 + sub-urban) driving cycle.
Figure 9 illustrate the efficiency of the motor and its controller, one can notice that there is not a great difference between the FOC and the DTC, the DTC-SVM technique represent less chattering compared to the two preceding techniques, this advantage confirms well that DTCSVM is a good candidate if one wants to make the optimization of the total energy of the vehicle.

Figure 10 shows the induction motor flux for conventional DTC and DTC-SVM controller, in the beginning of the simulation process, the nominal flux is applied to the induction motor drive until it reaches its steady state. One can confirm that the system is stable for the two control techniques, with elimination of the chattering for DTC-SVM.

\section{CONCLUSION}

This paper dealt with the comparative analysis of three control schemes for electric vehicles efficiency improvement; namely: FOC, DTC, and DTC-SVM. These control schemes were simulated using an induction motor model combined the vehicle aerodynamics. The DTC-SVM control can achieve the complete decoupled control of torque and flux and significant torque ripple reduction. Compared with the conventional DTC and FOC control methods, it has low torque ripple, low current distortion and high-performance dynamic characteristics. The limited power supply in EV requires a high efficiency electrical drive system. The drive for such a system must have a quick response and simple configuration. A suitable control strategy having the above mentioned features for the electrical drive is the DTC-SVM technique.

\section{APPENDIX}

RATED DATA OF THE SimUlated INDUCTION MOTOR

$$
\begin{gathered}
37 \mathrm{~kW}, 50 \mathrm{~Hz}, 400 / 230 \mathrm{~V}, 64 / 111 \mathrm{~A}, 24.17 \mathrm{Nm}, 2960 \mathrm{rpm} \\
R_{s}=85.1 \mathrm{~m} \Omega, R_{r}=65.8 \mathrm{~m} \Omega \\
L_{s}=31.4 \mathrm{mH}, L_{r}=29.1 \mathrm{mH}, L_{m}=29.1 \mathrm{mH} \\
J=0.23 \mathrm{~kg} . \mathrm{m}^{2}
\end{gathered}
$$

EV Mechanical AND AERodynamic PARAMETERS

$$
\begin{gathered}
m=1540 \mathrm{~kg} \text { (two } 70 \mathrm{~kg} \text { passengers) }, A=1.8 \mathrm{~m}^{2}, r=0.3 \mathrm{~m} \\
\mu_{r r 1}=0.0055, \mu_{r r 2}=0.056, C_{a d}=0.19, G=104, \eta_{g}=0.95 \\
T=57.2 \mathrm{Nm} \text { (stall torque), } v_{0}=4.155 \mathrm{~m} / \mathrm{sec} \\
g=9.81 \mathrm{~m} / \mathrm{sec}^{2}, \rho=0.23 \mathrm{~kg} / \mathrm{m}^{3}
\end{gathered}
$$

\section{REFERENCES}

[1] B. Singh and al., "Direct torque control: A practical approach to electric vehicle," in Proceedings of the IEEE PCI'06 India Conference, India, 4 pp., April 2006.

[2] J. Kim et al., "Dual-inverter control strategy for high-speed operation of EV induction motors," IEEE Trans. Industrial Electronics, vol. 51, ${ }^{\circ} 2$, pp. 312-320, April 2004.

[3] T. Jun Fu and al., "Torque control of induction motors for hybrid electric vehicles," in Proceedings of the IEEE ACC'06, Minneapolis (USA), pp. 5911-5916, Jun 2006.

[4] M.P. Kazmierkowski et al., Automatic Control of Converter Fed Drives," Elsevier: Amsterdam, 1994. 

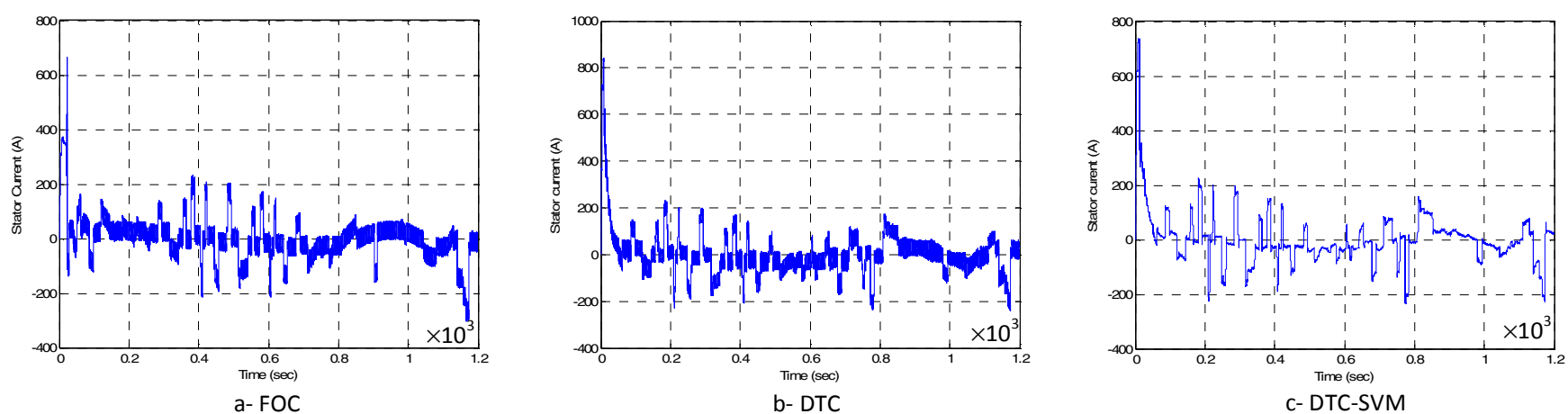

Fig. 7. Stator current.
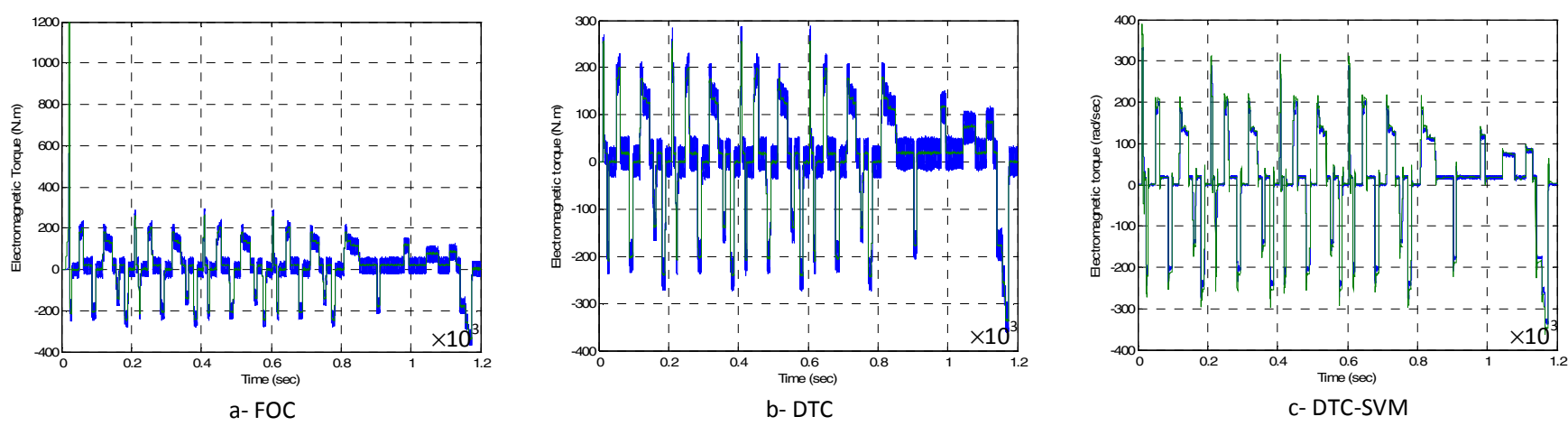

Fig. 8. Electromagnetic torque.
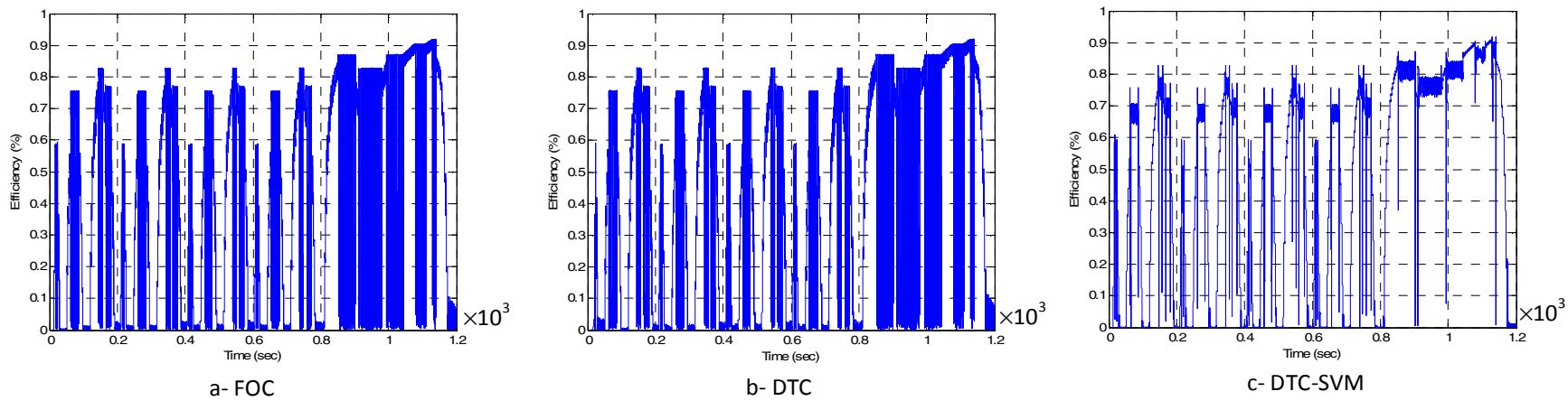

Fig. 9. Efficiency of the motor and its controller.

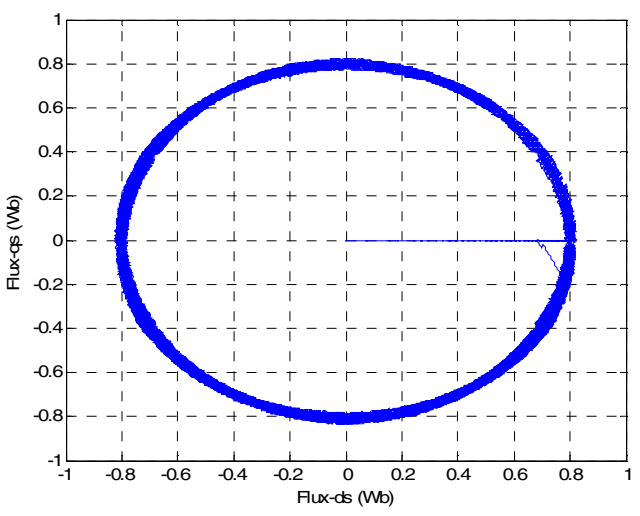

(a) DTC

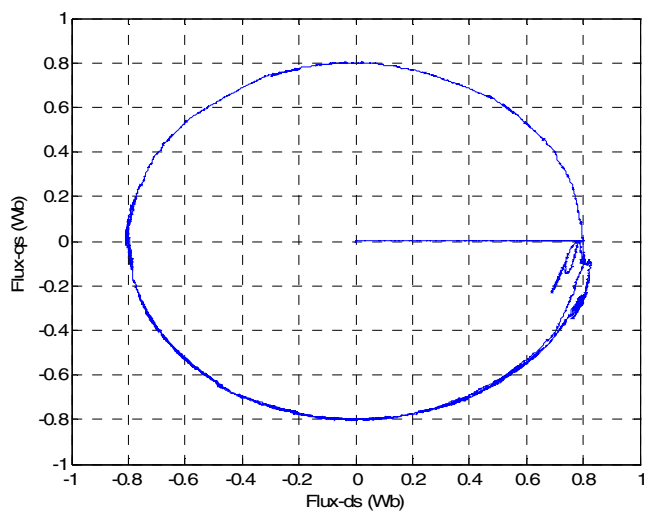

(b) DTC-SVM

Fig. 10. Flux trajectories. 
[5] G.S. Buja et al., "Direct torque control of PWM Inverted-Fed AC Motors - A Survey," IEEE Trans. Industrial Electronics, vol. 51, n ${ }^{\circ}$, pp. 744-757, August 2004.

[6] M. Zelechowski et al., "Controller design for direct torque controlled space vector modulation (DTC-SVM) induction motor drives," in Proceedings of the IEEE ISIE'05, Dubrovnik (Croatia), pp. 951-956, June 2005.

[7] A. Haddoun, M.E.H. Benbouzid and D. Diallo, "A loss-minimization DTC scheme for EV induction motors," IEEE Trans. Vehicular Technology, vol. 56, n ${ }^{\circ} 1$, pp. 81-88, January 2007

[8] J. Larminie, Electric Vehicle Technology Explained. Wiley: Oxford, 2003.

[9] T.J. Ren et al., "Robust speed-controlled induction motor drive based on recurrent neural network," Electric Power Systems Research, vol. 76, pp. $1064-1074,2006$.

[10] A. Benchaïb et al., "Real-time sliding mode observer and control of induction motor," IEEE Trans. Industrial Electronics, vol. 46, n ${ }^{\circ}$, pp. 128-138, February 1999.

[11] J. Faiz et al., "Sensorless direct torque control of induction motors used in electric vehicle," IEEE Trans. Energy Conversion, vol. 18, n ${ }^{\circ} 1, \mathrm{pp}$. $1-10$, March 2003

[12] J. Holtz., "Pulsewidth modulation for electronic power conversion", Proceedings of the IEEE, Vol. 82, pp. 1194-1214, August 1994.

[13] K. Zhou et al., "Relationship between space-vector modulation and three-phase carrier-based PWM: A comprehensive analysis", IEEE Trans. Industrial Electronics, vol. 49, n 1, pp. 186-195, February 2002.

[14] Y. Xue et al., "A low cost stator flux oriented voltage source variable speed drive", in Proceedings of the IEEE IAS Annual Meeting'90, Seattle (USA), vol. 1, pp. 410-415, October 1990.

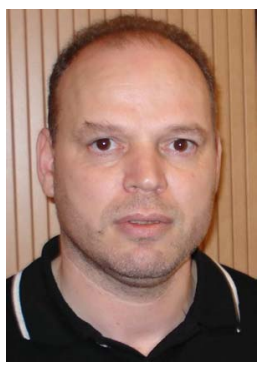

Abdelhakim Haddoun was born in Constantine, Algeria, in 1967. He received the B.Sc. and the M.Sc. degrees in Electrical Engineering, from the University of Batna, Algeria, in 1993 and 1999 respectively. In 2000, he joined the Electrical Engineering Department of the University of Oum El Bouaghi, Algeria, as a Teaching Assistant.

$\mathrm{He}$ is currently pursuing Ph.D. studies on electric vehicle control and power management.

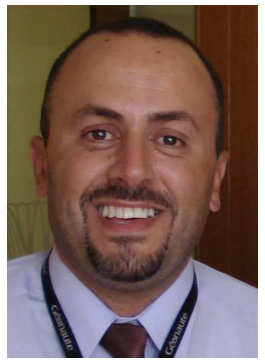

Mohamed El Hachemi Benbouzid (S'92-M'95SM'98) was born in Batna, Algeria, in 1968. He received the B.Sc. degree in electrical engineering from the University of Batna, Batna, Algeria, in 1990, the M.Sc. and Ph.D. degrees in electrical and computer engineering from the National Polytechnic Institute of Grenoble, Grenoble, France, in 1991 and 1994, respectively, and the Habilitation à Diriger des Recherches degree from the University of Picardie "Jules Verne," Amiens, France, in 2000.

After receiving the $\mathrm{Ph} . \mathrm{D}$. degree, he joined the Professional Institute of Amiens, University of Picardie "Jules Verne," where he was an Associate Professor of electrical and computer engineering. In September 2004, he joined the University Institute of Technology (IUT) of Brest, University of Western Brittany, Brest, France, as a Professor of electrical engineering. His main research interests and experience include analysis, design, and control of electric machines, variable-speed drives for traction and propulsion applications, and fault diagnosis of electric machines.

Prof. Benbouzid is a Senior Member of the IEEE Power Engineering, Industrial Electronics, Industry Applications, Power Electronics, and Vehicular Technology Societies. He is an Associate Editor of the IEEE TRANSACTIONS ON ENERgY CONVERSION, the IEEE TRANSACTIONS ON INDUSTRIAL ELECTRONICS, the IEEE TRANSACTIONS ON VEHICULAR TECHNOLOGY, and the IEEE/ASME TRANSACTIONS ON MECHATRONICS.

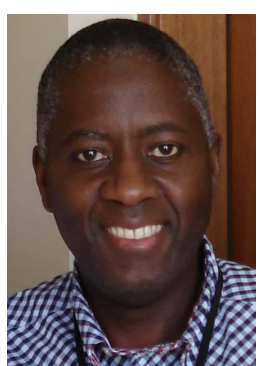

Demba Diallo (M'99-SM'05) was born in Dakar, Senegal, in 1966. He received the M.Sc. and Ph.D. degrees both in Electrical and Computer Engineering, from the National Polytechnic Institute of Grenoble, France, in 1990 and 1993 respectively.

From 1994 to 1999, he worked as a Research Engineer in the Laboratoire d'Electrotechnique de Grenoble, France, on electrical drives and active filters (hardware and software). In 1999 he joined the University of Picardie "Jules Verne" as Associate Professor of Electrical engineering. In September 2004, he joins the IUT of Cachan, University of Paris Sud P11 as an Associate Professor of Electrical Engineering. He is with the Laboratoire de Génie Electrique de Paris. In December 2005, he received the "Habilitation à Diriger des Recherches" degree from the University of Paris Sud P11. His current area of research includes advanced control techniques and diagnosis in the field of ac drives.

D. Diallo is a Senior Member of the IEEE Industry Applications, Vehicular Technology and Control Systems Societies.

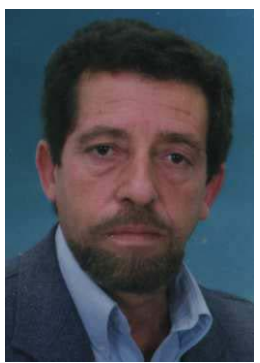

Rachid Abdessemed was born in Batna, Algeria, in 1951. He received the M.Sc. and Ph.D. degrees in Electrical Engineering, from Kiev Polytechnic Institute, Ukraine, in 1978 and 1982 respectively.

$\mathrm{He}$ has been working for more than eighteen years at the University of Batna where he is a Professor in the Electrical Engineering Department. Currently, he is the Director of the Electrical Engineering Laboratory. His current area of research includes design and control of induction machines, reliability, magnetic bearings, and renewable energy.

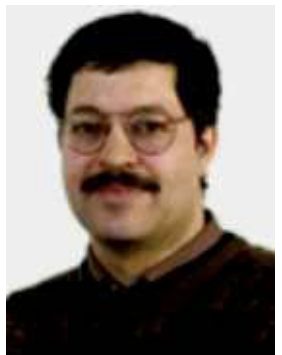

Jamel Ghouili was born in Ghardimaou, Tunisia, in 1962. $\mathrm{He}$ is currently Professor at the University of Moncton, Canada, where he is responsible of the power electronics and drives Teaching and Research program since 2000 . He received the B.Sc., the M.Sc. and the Ph.D. degrees from University of Québec at TroisRivières, Canada, in 1986, 1998 and 2004 respectively. Early in his career, he served as Professor at Ecole Polytechnique de Masuku, Gabon. His main research interests include power converters, ac drives, DSP and FPGA control, sensorless control, EV/HEV drives, fuzzy logic and neural network applications in power electronics and drives.

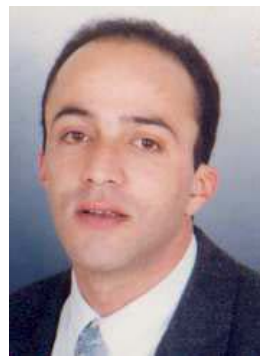

Kamel Srairi was born in Batna, Algeria, in 1967. $\mathrm{He}$ received the B.Sc. degree in Electrical Engineering, in 1991, from the University of Batna, Algeria; the M.Sc. degree in Electrical and Computer Engineering, from the National Polytechnic Institute of Grenoble, France, in 1992; and the Ph.D. degree also in Electrical and Computer Engineering, from the University of Nantes, France, in 1996.

After graduation, he joined the University of Biskra, Algeria, where he is a Professor in the Electrical Engineering Department His main research interests include analysis, design, and control of electric machines. 